\title{
A NEW PARADIGM FOR THE IN VITRO SIMULATION OF SIDEWAYS FALL LOADING OF THE PROXIMAL HUMAN FEMUR
}

\author{
LORENZO ZANI*, LUCA CRISTOFOLINI ${ }^{\dagger}$, , \\ MATEUSZ MARIA JUSZCZYK ${ }^{*, \dagger}$, LORENZO GRASSI* \\ and MARCO VICECONTI \\ *Medical Technology Laboratory \\ Rizzoli Orthopaedic Institute \\ Bologna, Italy \\ ${ }^{\dagger}$ Department of Industrial Engineering \\ University of Bologna, Italy \\ Department of Mechanical Engineering \\ University of Sheffield, UK \\ \$luca.cristofolini@unibo.it
}

Received 2 March 2012

Revised 25 May 2013

Accepted 31 May 2013

Published 15 July 2013

\begin{abstract}
Although the direction of loads applied to the proximal human femur is unpredictable during sideways fall, most in vitro and numerical simulations refer to a single loading condition $\left(15^{\circ}\right.$ internal rotation; $10^{\circ}$ adduction), which has been anecdotally suggested in the 1950 s. The aim of the present study was to improve in vitro simulations of sideways falls on the proximal femur.

An in vitro setup was developed that allowed exploring a range of loading directions $\left(+/-90^{\circ}\right.$ internal-external rotation; $0^{\circ}-50^{\circ}$ adduction). To enable accurate control of the loading conditions (direction and magnitude of all load components applied to the femur), the setup included a number of low-friction linear and rotary bearings. The setup was instrumented with an axial and a torsional load cell, three displacement transducers and a rotation transducer to monitor the most significant components of load/displacement during testing. The strain distribution was measured on the bone surface $(16$ triaxial strain gauges, 2,000 Hz). Fracture was recorded with a high-speed camera.

The setup was successfully tested on a cadaveric femur non-destructively (12 loading configurations) and destructively ( $15^{\circ}$ internal rotation; $10^{\circ}$ adduction). All measurements were highly repeatable (the displacements of the femoral head varied by $<2 \%$ between repetitions; the tilt in the frontal plane by $<0.05^{\circ}$; and strain varied on average $0.34 \%$ between repetitions). The displacement of the femoral head varied by over $50 \%$ when the same force was applied in different directions. Principal strains at the same location varied by over $70 \%$, depending on the direction of the applied force. The high-speed video enabled the identification of the point of fracture initiation.
\end{abstract}


This study has shown that a new paradigm for testing the proximal femur (including improved testing conditions and a variety of loading configurations) can provide more accurate and more extensive information about the state of strain.

Keywords: Biomechanics; proximal femur fracture; sideways fall; bone strain distribution; in vitro destructive test.

\section{List of Acronyms and Abbreviations}

$\varepsilon_{1} \quad$ maximum principal strain

$\varepsilon_{2} \quad$ minimum principal strain

$\theta_{P} \quad$ angle of the principal planes (counter-clockwise)

A1 strain gauge on the Anterior side, below the lesser trochanter

A3 strain gauge on the Anterior side, along the diaphysis

$\mathrm{AH} \quad$ strain gauge on the Anterior side of the Head

AN strain gauge on the Anterior side of the Neck

BL Biomechanical Length of the Femur

BW Body Weight

$\mathrm{CoV} \quad$ Coefficient of Variation (standard deviation expressed as a $\%$ of the average)

CT Computed Tomography

DEXA Dual Energy X-ray Absorptiometry

FE Finite Element

HD Diameter of the femoral Head

L1 strain gauge on the Lateral side, below the lesser trochanter

L3 strain gauge on the Lateral side, along the diaphysis

LH strain gauge on the Lateral side of the Head

LN strain gauge on the Lateral side of the Neck

LVDT Linear Variable Differential Transformer (displacement transducer)

LVDT-AP LVDT measuring the displacements of the femoral head in the antero-posterior direction

LVDT-PD LVDT measuring the displacements of the femoral head in the proximal-distal direction strain gauge on the Medial side, along the diaphysis

$\mathrm{MN}$

P1

P3

$\mathrm{PH}$

$\mathrm{PN}$ strain gauge on the Medial side of the Head strain gauge on the Medial side of the Neck strain gauge on the Posterior side, below the lesser trochanter strain gauge on the Posterior side, along the diaphysis strain gauge on the Posterior side of the Head

VPH-OP Virtual Physiological Osteoporotic Human project (http://www.vphop.eu/) 


\section{Introduction}

The femur is the bone which is most frequently fractured during a human's lifespan. ${ }^{1,2}$ Most femoral fractures are localized in the proximal metaphysis. ${ }^{2}$ Consequences of fractures in the proximal femoral metaphysis include immobilization, necrosis, need for total joint replacement, permanent disability and indirectly death (especially in elderly subjects ${ }^{1}$ ). Most fractures in the proximal femoral metaphysis are a consequence of accidental falls. ${ }^{3,4}$ For these reasons, fractures of the proximal femur have been investigated clinically, but also in vitro and numerically, so as to elucidate the aetiology of such fractures, ${ }^{5-9}$ and also to improve prevention ${ }^{9}$ and treatment. ${ }^{10}$

There is a general agreement on the mechanism leading to fractures in the proximal femoral metaphysis during falls; in most cases, the subject falls on his/her side hitting the floor with the side of the hip. ${ }^{11-13}$ As a consequence, a force is delivered to the greater trochanter through the soft tissues, which is more or less perpendicular to the long axis of the femur. ${ }^{5}$ At the same time, part of the load is transmitted from the pelvis to the femoral head. This loading condition tends to generate a large moment in the frontal plane in the proximal femur. No information is available about the direction of the forces applied during a sideways fall (in fact, falling itself is an unpredictable event).

The first in vitro simulation of sideways fall loading of the femur is due to Backman $^{5}$ : the femur shaft was held in a metallic clamp, free to rotate in the frontal plane, while a force was applied to the femoral head with the greater trochanter resting on a clay cushion. The femur was adducted by $10^{\circ}$ and internally rotated by $15^{\circ}$. Most of the subsequent in vitro and numerical studies replicated similar loading conditions. $^{14-21}$

Many experimental studies have been designed to investigate the effect of hip stems. $^{22}$ Therefore, the loading configuration and the strain measurement procedures proposed in the literature mostly focus on the diaphysis and might not be suitable to investigate the proximal metaphysis. ${ }^{23}$ The stress/strain distribution in the femur has been extensively studied in the past ${ }^{24-26}$ : in most cases walking, stairclimbing and other standing motor tasks have been simulated. The strain distribution in the proximal femoral metaphysis has rarely been investigated, only under simulated single-leg stance, ${ }^{27,28}$ while the failure load has often been measured in vitro, ${ }^{14-16,18-21,29}$ only limited information has been published concerning the strain distribution. To the authors' knowledge, the strain distribution in the proximal femur has been in vitro measured only once during a simulated fall (a sideways load was delivered to the femur with nine strain gauges, adducted by $30^{\circ}$ and internally rotated by $30^{\circ 30}$ ) ; this is the only work where numerically predicted and experimentally measured strains were compared, in one specimen, and for one loading configuration. ${ }^{30}$

We are not aware of any studies where the relevance of the loading configuration proposed $^{5}$ is shown. Conversely, as the force applied to the greater trochanter can be 
expected to span a relatively large angle depending on the position of the falling subject, it is difficult to assume that a single direction of loading can represent all possible types of sideways falls. It is not known if different directions of the loads applied to the proximal femur would result in different risks of fractures in the proximal femoral metaphysis. In addition, in some of the in vitro studies, the loading conditions are ill-posed: if the femur is over-constrained (e.g., Refs. 31 and 32), unknown loads are generated by the constraints.

The aim of the present study was to develop a novel method to replicate in vitro the loads acting on a femur during a sideways fall, in a way that allows:

(a) Accurate control of the in vitro loading conditions (direction and magnitude of all the load components applied to the femur).

(b) Accurate measurement of the most significant components of translation/ rotation of the femur under load

(c) Measuring the strain distribution on the bone surface under load.

(d) Exploring a range of loading directions corresponding to the fact that the direction of the impact load delivered to the femur is unknown.

\section{Material and Methods}

\subsection{Overview}

The in vitro setup simulated the traumatic event of a fall on the side, where a force is applied to the femoral head (by the pelvis) and to the greater trochanter (by the floor). As the actual directions of the applied forces are unknown, a set of simplified loading configurations was explored. A single force was applied to the femoral head at different directions, while the greater trochanter (resting on a dedicated support) received the reaction force that simulated the traumatic event of a fall. An in vitro setup was designed that allowed application of the two forces above, while all other degrees of freedom were allowed by means of low-friction bearings. Muscle forces were not simulated, as experimental and finite element (FE) studies indicated they do not significantly alter the stress distribution in the proximal metaphysis. ${ }^{33}$ The entire setup was fully instrumented so as to monitor the displacements/rotations of all the unconstrained degrees of freedom. The testing setup and the protocol were assessed on one cadaveric femur.

\subsection{Preparation of the test specimen}

A fresh, frozen left femur specimen was obtained from a donor who did not suffer from musculoskeletal pathologies nor cancer (male; Caucasian; height of $188 \mathrm{~cm}$; body weight $(\mathrm{BW})$ of $95 \mathrm{~kg}$; died at 65 years old, cause of death myocardial infarction). The specimen was obtained through an ethically approved international donation program (IIAM, Jessup, PA, USA). The femur was CT-scanned to document bone quality and lack of abnormality or defects. Anatomical dimensions 
were measured. ${ }^{34,35}$ To preserve tissue hydration, the femur was wrapped in moistened cloths during testing.

- The biomechanical length (BL) was measured between the trochanteric fossa and the intercondylar fossa ( $\mathrm{BL}=390 \mathrm{~mm}$ for the specimen under investigation).

- The diameter of the head was measured five times along different directions; the average head diameter (HD) was computed ( $\mathrm{HD}=40.5 \mathrm{~mm}$ for the specimen under investigation).

To enable consistent alignment, an anatomical reference frame was marked on the femur ${ }^{34-36}$ : this included univocal definition of the internal-external rotation, and identification of the sagittal and frontal planes. The distal part of the femur was resected. The remaining proximal part of the femur was potted with acrylic bone cement in an aluminium pot (100-mm deep) so that $33 \%$ of the biomechanical length protruded from the pot (Fig. 1).
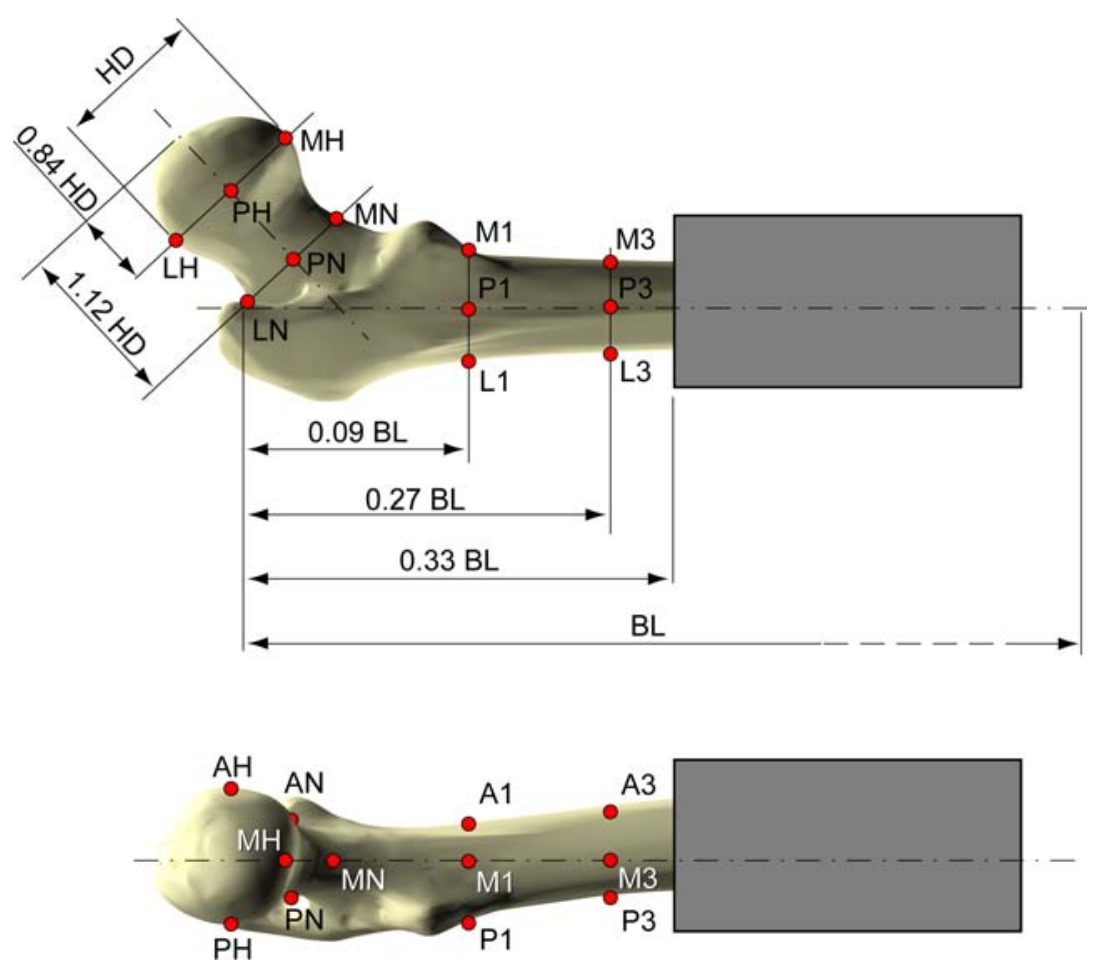

Fig. 1. Sketch of a left femur with an indication of the position of the strain gauges: posterior and medial views. To allow comparable positioning between specimens, the four levels where strain gauges were placed were defined as a fraction of the femur dimensions (biomechanical length, BL; head diameter, HD). The positions around the head and neck of strain gauges $\mathrm{MH}, \mathrm{MN}, \mathrm{LH}$ and $\mathrm{LN}$ correspond to the frontal plane. ${ }^{13,14}$ The positions around the head and neck of the strain gauges $\mathrm{AH}, \mathrm{AN}, \mathrm{PH}$ and $\mathrm{PN}$ correspond to the mid thickness of the neck at the corresponding level. The positions around the diaphysis of the strain gauges A1, L1, P1, M1, A3, L3, P3 and M3 correspond to the mid thickness of the diaphysis at that level. 

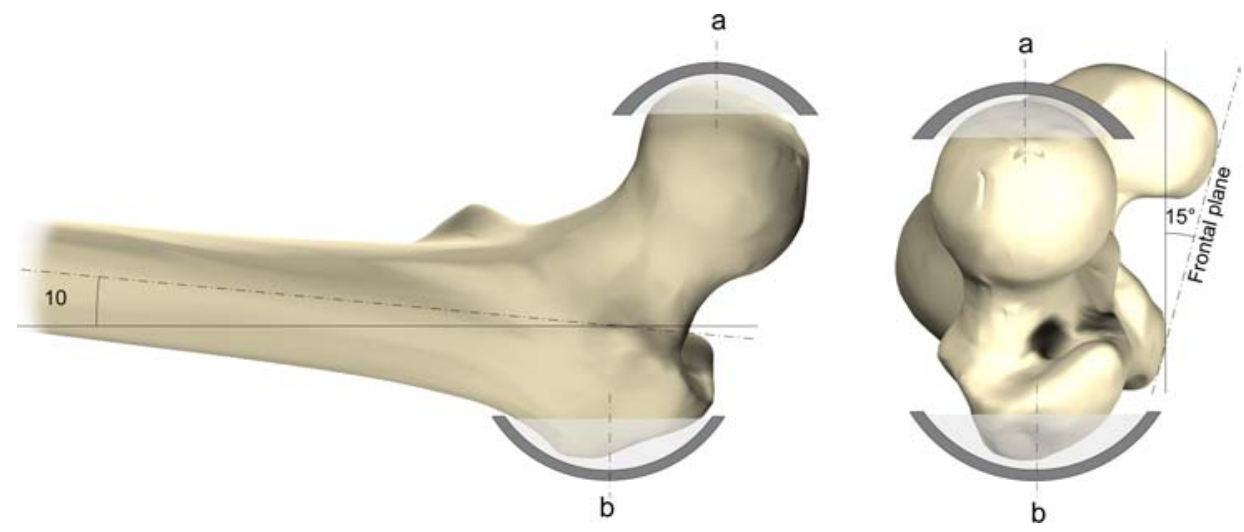

Fig. 2. Left femur viewed from anterior and from superior. In these images, the femur is tilted by $10^{\circ}$ in adduction, and internally rotated by $15^{\circ}$. This schematic shows the position of the aluminium caps mounted on the femoral head and on the greater trochanter to avoid local crushing. The cap on the head (a) was concentric with the original femoral head and covered an angle of $60^{\circ}$. The cap on the greater trochanter (b) was centred on the intersection of the frontal and sagittal planes of the femoral diaphysis and covered an angle of $50^{\circ}$.

To avoid local crushing, aluminium spherical caps were custom-manufactured and applied with bone cement to the femoral head and the greater trochanter (Fig. 2).

\subsection{In vitro loading setup}

In order to ensure accurate control on the applied loads, the loading setup was designed so as to avoid any over-constraint of the test specimen. It also allowed testing the same femur specimen with different loading directions, and to able to be adjusted in the desired configurations with ease and accuracy (Fig. 3).

The femur was constrained distally, medial side up. A force was applied by the actuator of the testing machine (Mod. 8502, Instron, Canton, MA, USA) to the femoral head. The greater trochanter rested on a dedicated flat support. To avoid over-constraining the specimen (which would result in an ill-posed loading condition), the following steps were taken:

- The distal constraint consisted of a hinge that allowed free tilt of the femur in a vertical plane (when the femur is at $0^{\circ}$ internal rotation, the vertical plane of the loading setup corresponds to the frontal plane of the femur). All other rotations and translations of the distal extremity were constrained.

- The greater trochanter (protected by its aluminium spherical cap) rested on a flat surface, which was supported by two orthogonal linear bearings that eliminated any horizontal force component. The aluminium cap protecting the greater trochanter was free to rotate against the flat surface of the upper linear bearing.

- Load was applied to the femoral head (protected by its aluminium spherical cap) by the actuator of the testing machine through a system of linear bearings that 


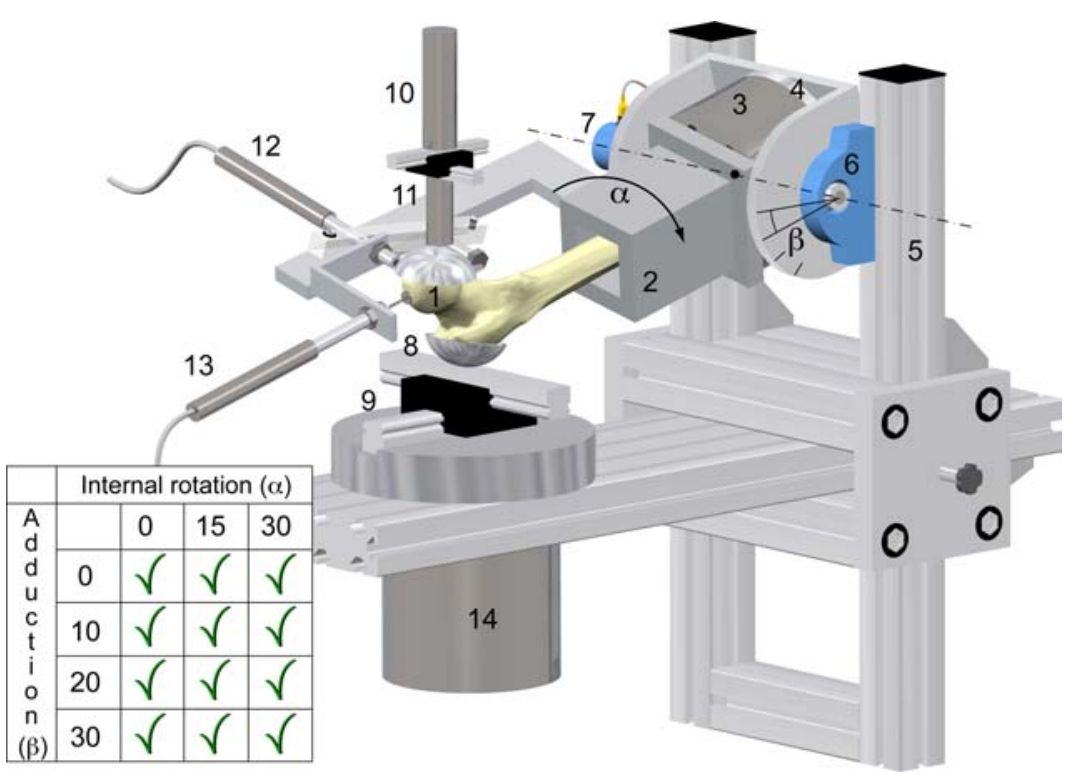

Fig. 3. In vitro setup with a left femur. The femur (1) was held through its distal pot (2). Also visible are: the load cell (3) to measure the torque about the femoral axis. The internal rotation angle (alpha) could be adjusted (4). The adduction angle (beta) was selected adjusting the height of the distal constraint (5). Thanks to a bearing (6), the femur was free to tilt (small fluctuations of the angle beta, measured by a digital encoder (7). The flat support (8) of the greater trochanter and its linear bearings (9) are visible. Load was applied to the femoral head by the testing machine (10) through a system of linear bearings (11). Two transducers measured the displacement of the head: LVDT-AP (12) in the antero-posterior direction, LVDT-PD (13) in the proximal-distal direction. The setup was mounted on the load cell (14) of the testing machine.

eliminated any horizontal force component. The aluminium cap protecting the femoral head could rotate against the flat surface at the end of the actuator.

- All linear and rotary bearings were selected from low-friction series to minimize the presence of any undesired load component.

- Therefore, pure vertical forces were delivered. Because of the adjustable alignment of the femur (see below), such vertical forces acted at the desired angles on the femoral head and on the greater trochanter.

The distal constraint included a system of rails, clamps and goniometers that allowed placing the femur at the desired angles: the internal-external rotation angle (alpha) could be continuously adjusted within $+/-90^{\circ}$; such an angle could be measured with a graduate scale, and it could be locked through a clamp. The adduction angle (beta) could be continuously adjusted in the range of $0^{\circ}-50^{\circ}$ by adjusting the height of the distal constraint along the vertical rails. In the present study, three values were selected for the internal rotation $\left(0^{\circ}, 15^{\circ}\right.$ and $\left.30^{\circ}\right)$, while four values were used for the adduction angle $\left(0^{\circ}, 10^{\circ}, 20^{\circ}\right.$ and $\left.30^{\circ}\right)$. All 12 combinations of 
these angles were tested in a $4 \times 3$ full factorial scheme (Fig. 3). Hence, the classical configuration ( $15^{\circ}$ internal rotation; $10^{\circ}$ adduction) was also tested.

The in vitro setup included the following transducers, which were selected so that they could withstand both the non-destructive and destructive tests:

- The load cell of the testing machine (8502, Instron, Canton, MA, USA: 5-kN full scale; $0.5 \%$ precision), measuring the force delivered to the femoral head.

- The LVDT of the Instron actuator (50-mm range; $0.5 \%$ precision), which measured the vertical deflection of the femoral head.

- Two high-precision LVDTs (GHSA750-500, Macro Sensors, Pennsauken, JN, USA) with a total range of $+/-12.5 \mathrm{~mm}$, and a precision of $10 \mu \mathrm{m}$ in the range of $+/-5 \mathrm{~mm}$ used in this study. The first LVDT (LVDT-AP) measured the relative movement of the femoral head in antero-posterior direction; the second one (LVDT-PD) in the proximal-distal direction during load application. These LVDTs were mounted on support frames that were connected to the distal pot of the femur, so that they had a consistent alignment with respect to the bone for any testing configuration.

- A rotary digital encoder (CH25-5000, Celesco, Chatsworth, CA, USA), with a precision of $0.072^{\circ}$ in the range of $30^{\circ}$ was used in this study. The encoder was fixed on the shaft of the bearing and measured the tilt of the distal end of the specimen in the vertical plane during load application.

- A torsional load cell (MTRX500NM005, Allemano, Turin, Italy; 500-Nm full scale; $0.5 \%$ precision) was placed between the pot and the distal constraint. Its center was placed at the center of the bearing allowing rotation in the vertical plane. It measured the reaction torque about the femoral long axis generated during testing at the distal extremity.

The signals from all the transducers above were fed into a 60-channel data logger (System-6000, Vishay Micro-Measurement, Raleigh, NC, USA), which also recorded the signals from the strain gauges (see below). All signals were sampled at $2,000 \mathrm{~Hz}$, with a low-pass cut-off of $50 \mathrm{~Hz}$.

\subsection{Loading rates}

The femur was loaded in position control by the testing machine at different speeds.

- High-strain rate: the actuator speed was tuned so that the average strain-rate in the most stressed regions during the loading ramp was 50,000 microstrain/s. As bone tissue fails when strain exceeds $7,000-10,000$ microstrain, ${ }^{37}$ such a strain rate would generate failure in the order of $0.2 \mathrm{~s}$. This is the typical timescale of physiological and para-physiological loading, ${ }^{38,39}$ and has been proposed in the past for in vitro testing. ${ }^{40,41}$

- Low-strain rate: to enable accurate measurements, load was applied also at the lower-bound value for physiological strain rates. In this case, the load ramp was 
10 times slower than high-strain-rate. This rate has been proposed in the past for in vitro testing. ${ }^{34,41}$

\subsection{Non-destructive testing}

All 12 loading configurations (corresponding to the different combinations of internal rotation and adduction) were tested on the same femur. Each configuration was tested six times, dismounting and realigning the entire loading setup between repetitions (3 mins' recovery between repetitions).

In order to avoid bone damage due to repeated loading, the force applied by the testing machine was tuned so that the largest strain (absolute value) recorded by the strain gauges (see below) was 900-1,000 microstrain in the most stressed regions. This is approximately one-tenth the failure strain of bone tissue $(7,000-$ 10,000 microstrain $^{37}$ ).

To enable better control of the applied loads, non-destructive tests were carried out at the low-strain rate, similarly to those in Refs. 34 and 41. The maximum load was held for $0.2 \mathrm{~s}$ before unloading to allow for a plateau for stable strain recording. Strain signals were averaged over 0.1 se (200 data points) to reduce error due to noise.

\subsection{Destructive testing}

A destructive test was carried out with a single monotonic ramp up to macroscopic failure of the femur. To mimic typical conditions leading to femur fracture, the destructive test was carried out using the high-strain rate. During destructive
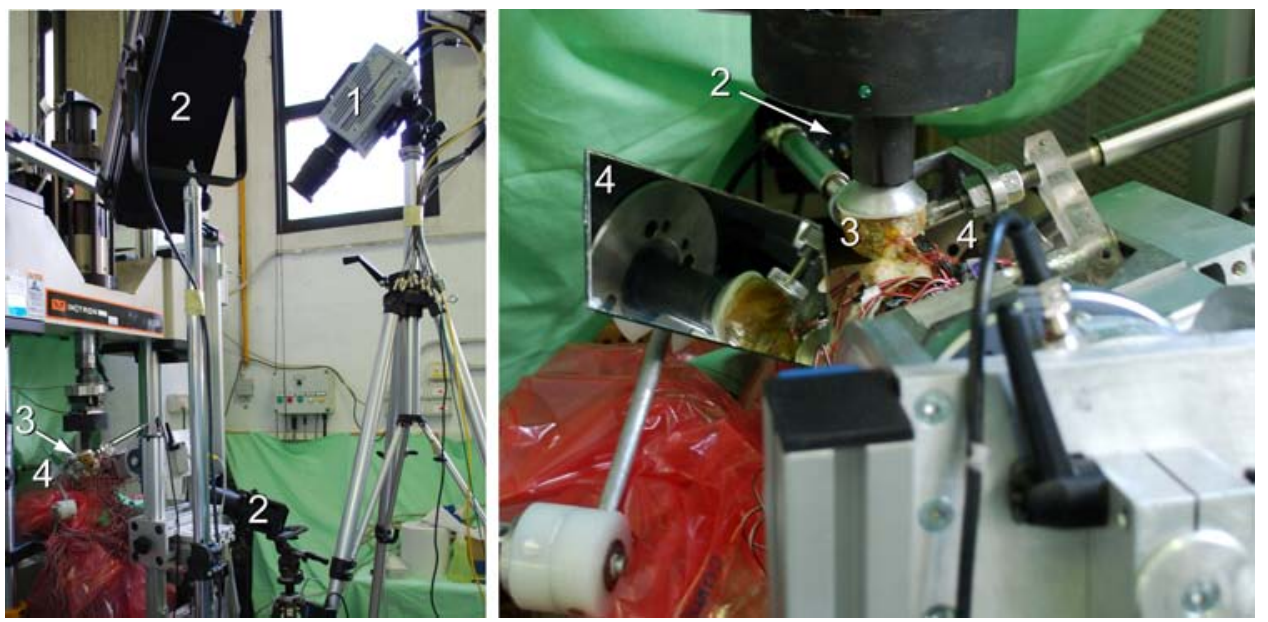

Fig. 4. Experimental setup for the destructive test. Left: overview of the testing setup where the highspeed camera (1) was mounted on a high tripod (directly facing the medial part of the femur), together with the light sources (2); the bone specimen (3) is visible under the testing machine. Right: femur (3) mounted on the testing machine ( $15^{\circ}$ internal rotation; $10^{\circ}$ adduction); one of the two mirrors (4) is clearly visible near the femur, while the other is partially hidden (they were oriented so as to reflect the postero-lateral and antero-lateral sides of the femur). 
testing, the configuration chosen was $15^{\circ}$ internal rotation and $10^{\circ}$ adduction, consistent with the literature. ${ }^{42}$

As bone fracture occurs in milliseconds, the destructive test was filmed using a high-speed camera (Fastcam SA3, Photron, San Diego, CA, USA) at 10,000 frames per second, following a validated procedure. ${ }^{43}$ The camera pointed at the medial side of the specimen (from top, Fig. 4), while two mirrors allowed viewing in the same frame also the antero-lateral and postero-lateral sides of the femur, similar to that in Ref. 43. Images had a resolution of $512 \times 304$ pixels. Three high-intensity light sources $(1,000 \mathrm{~W}+300 \mathrm{~W}+300 \mathrm{~W})$ were used to enhance lighting, thus allowing a short shutter setting and high aperture setting for optimal image sharpness.

\subsection{Strain measurement}

Bone strain was measured during the non-destructive and the destructive tests. Triaxial stacked strain gauges (C2A-06-031WW-350, Vishay Micro-Measurement, grid length of $3 \mathrm{~mm}$ ) were bonded at 16 locations (Fig. 1):

- At four distinct levels along the femur: around the head (close to the articular cartilage); around the neck (distal to the previous ones); around the proximal diaphysis (just below the lesser trochanter); further down the diaphysis;

- At each level, they covered the four sides of the femur (Anterior, Lateral, Posterior and Medial sides).

The actual position where the strain gauge was bonded was sometimes adjusted by up to $4 \mathrm{~mm}$, when small defects (pores, ridges or grooves) made the bone surface unsuitable for bonding a strain gauge.

The area for strain measurement was prepared with an established procedure for wet cadaveric specimens, ${ }^{44}$ which included:

1. Cleaning the surface from soft tissues with a scalp and sandpaper;

2. Accurate cleaning and degreasing first with ethanol, then with a cocktail of acetone and 2-propanol (RMS1, HBM, Darmstadt, Germany);

3. Filling the pores and waterproofing the bone surface with two layers of polyurethane protective (PU120, HBM);

4. Smoothening and removing the excess of polyurethane with fine sandpaper (\#400);

5. Bonding the strain gauges with cyanoacrylate glue (CC-33A, Kyowa); and

6. Protecting and waterproofing the strain gauges with three layers of polyurethane protective (PU120, HBM).

A grid excitation of $0.5 \mathrm{~V}$ was selected to avoid heating. Strains were recorded by the 60-channel data logger (System-6000), which also recorded the signals from all the other transducers above. 


\subsection{Statistics}

Principal strains $\left(\varepsilon_{1}\right.$ and $\left.\varepsilon_{2}\right)$ and the angle $\left(\theta_{P}\right)$ of the principal planes were obtained for each strain gauge, and a repetition of each loading configuration. As different load values were applied for the different loading configurations, to enable comparisons, the strain values were all scaled to a conventional load of $1 \mathrm{BW}$ (this is possible thanks to the high linearity found in the load-strain plots, see below).

To estimate the measurement repeatability (intra-specimen variability), the standard deviation of the principal strains $\left(\varepsilon_{1}\right.$ and $\left.\varepsilon_{2}\right)$ and angle $\left(\theta_{P}\right)$ was computed between repetitions, for each strain gauge and each loading configuration. The coefficient of variation (CoV: standard deviation expressed as \% of the average) was computed for each measurement location. To avoid fictitiously increasing the $\mathrm{CoV}$ with close-to-zero data, measurement locations where strain was lower than 100 microstrain were excluded.

All statistical analyses were performed using commercial software (Excel 12.2.8 with Statistical Analysis Toolpak, Microsoft, Redmond, WA, USA).

\section{Results}

\subsection{Non-destructive testing}

All 12 loading configurations were successfully tested. Depending on the loading configuration, the force applied to the femoral head was $672-1,158 \mathrm{~N}(0.72-$ $1.24 \mathrm{BW})$.

Both the displacements and the strain signals were highly linear (Fig. 5). The displacements of the femoral head recorded by the two LVDTs were highly repeatable ( $\mathrm{CoV}$ between repetitions of the same loading configuration on average $2 \%$ ). Also, the angle of rotation of the femur in the frontal plane measured by the distal encoder was highly repeatable (variation $<0.05^{\circ}$ between repetitions of the same loading configuration).

The deflections of the femoral head in all directions (Tables $1-3$ ), as well as the reaction torque about the femoral long axis (Table 4) varied according to the simulated loading configuration. The displacement of the femoral head varied by over $50 \%$ when the same force was applied in different directions. The tilt of the distal end of the specimen in the vertical plane (when the femur is at $0^{\circ}$ internal rotation, the vertical plane of the loading setup corresponds to the frontal plane of the femur) during load application never exceeded $0.1^{\circ}$. This is close to the sensitivity of the rotary digital encoder; variations between loading configurations were negligible.

Strain measurement repeatability was good: the CoV between replicates under the same conditions was on average $0.34 \%$ for the principal strains at all locations. Also, the angle $\left(\theta_{P}\right)$ of the principal planes varied on average by $0.16^{\circ}$ (standard deviation) between replicates under the same conditions.

Different strain patterns were observed for the different loading directions (Figs. 6 and 7). The value of principal strains at the same location on the femur 
L. Zani et al.
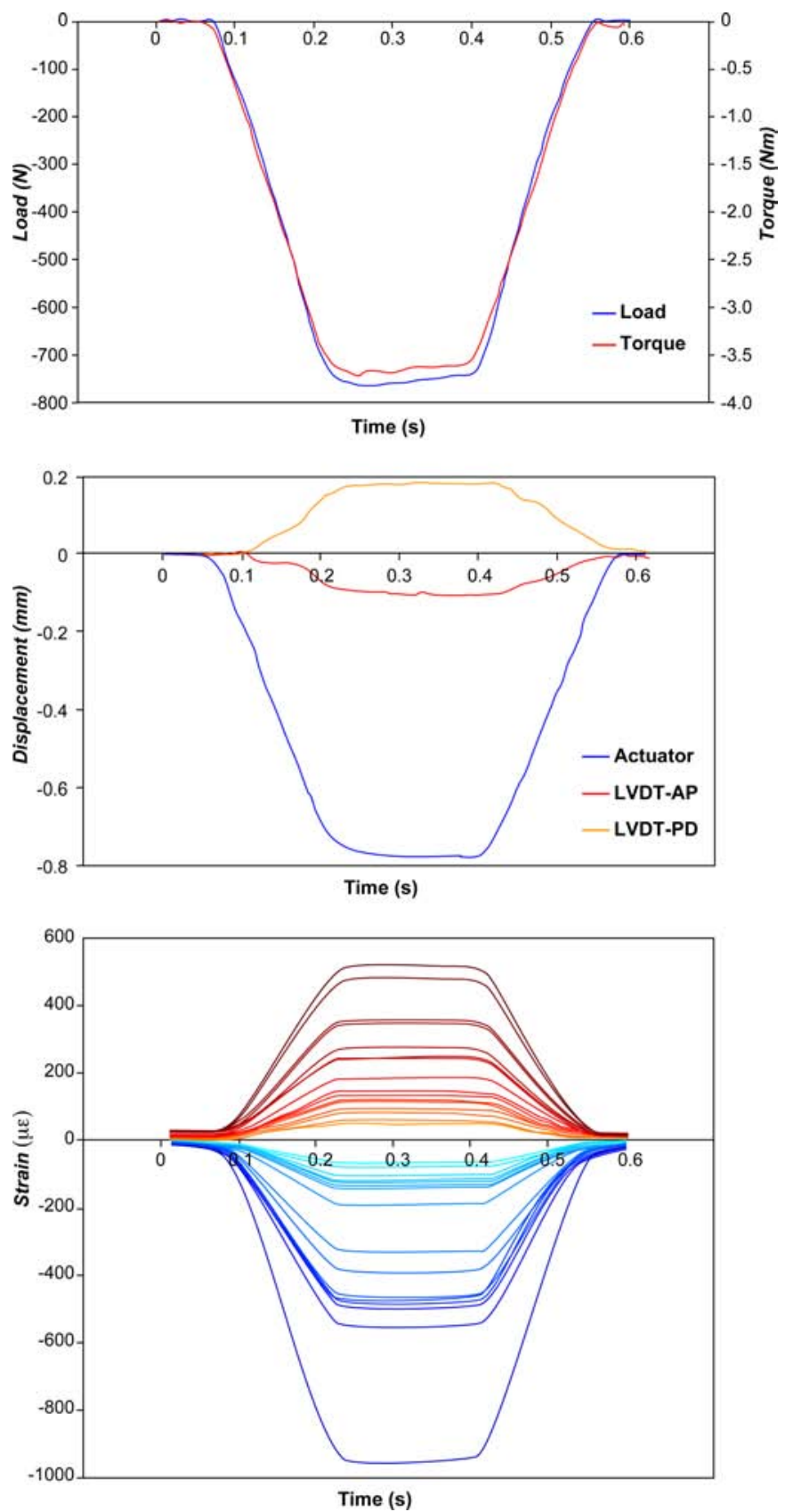

Fig. 5. (Color online) Plots of the recorded signals over time for a typical loading repetition when the femur was placed at $15^{\circ}$ internal rotation and $10^{\circ}$ adduction. Top: actuator force and reaction torque at the distal end (see setup in Fig. 3). Center: displacement of the actuator and of the femoral head in two directions (see setup in Fig. 3). Bottom: principal strains computed for the 16 triaxial strain gauges; the largest positive strain were found in the medial side of the neck (gauge MN), and the largest compressive strain was in the lateral side of the neck (gauge LN). 
Table 1. Deflection of the femoral head in a quasi-medial-lateral direction, measured by the Instron actuator (Fig. 3) for the 12 loading configurations. Average \pm standard deviation between six test repetitions is reported, in millimetres. Positive values indicate a displacement of the femoral head towards lateral. As different load values were applied for the different loading configurations, to enable comparisons, the readouts were all scaled to a conventional load of $1 \mathrm{BW}$ applied to the femoral head.

\begin{tabular}{cccc}
\hline & \multicolumn{3}{c}{ Internal rotation } \\
\cline { 2 - 4 } Adduction & $0^{\circ}$ & $15^{\circ}$ & $30^{\circ}$ \\
\hline $0^{\circ}$ & $0.782 \pm 0.002 \mathrm{~mm}$ & $0.546 \pm 0.013 \mathrm{~mm}$ & $0.431 \pm 0.002 \mathrm{~mm}$ \\
$10^{\circ}$ & $0.854 \pm 0.003 \mathrm{~mm}$ & $0.589 \pm 0.006 \mathrm{~mm}$ & $0.442 \pm 0.003 \mathrm{~mm}$ \\
$20^{\circ}$ & $0.779 \pm 0.014 \mathrm{~mm}$ & $0.628 \pm 0.008 \mathrm{~mm}$ & $0.524 \pm 0.004 \mathrm{~mm}$ \\
$30^{\circ}$ & $0.844 \pm 0.002 \mathrm{~mm}$ & $0.670 \pm 0.003 \mathrm{~mm}$ & $0.546 \pm 0.001 \mathrm{~mm}$ \\
\hline
\end{tabular}

Table 2. Deflection of the femoral head in the antero-posterior direction, measured by LVDT-AP (Fig. 3) for the 12 loading configurations. Average \pm standard deviation between six test repetitions is reported, in millimeters. Positive values indicate a displacement of the femoral head towards anterior. As different load values were applied for the different loading configurations, to enable comparisons, the readouts were all scaled to a conventional load of $1 \mathrm{BW}$ applied to the femoral head.

\begin{tabular}{ccrr}
\hline & \multicolumn{3}{c}{ Internal rotation } \\
\cline { 2 - 4 } Adduction & $0^{\circ}$ & $15^{\circ}$ & $30^{\circ}$ \\
\hline $0^{\circ}$ & $0.347 \pm 0.005 \mathrm{~mm}$ & $0.169 \pm 0.006 \mathrm{~mm}$ & $-0.014 \pm 0.002 \mathrm{~mm}$ \\
$10^{\circ}$ & $0.291 \pm 0.017 \mathrm{~mm}$ & $0.131 \pm 0.002 \mathrm{~mm}$ & $-0.082 \pm 0.014 \mathrm{~mm}$ \\
$20^{\circ}$ & $0.167 \pm 0.004 \mathrm{~mm}$ & $-0.007 \pm 0.006 \mathrm{~mm}$ & $-0.137 \pm 0.005 \mathrm{~mm}$ \\
$30^{\circ}$ & $0.060 \pm 0.007 \mathrm{~mm}$ & $-0.090 \pm 0.006 \mathrm{~mm}$ & $-0.246 \pm 0.015 \mathrm{~mm}$ \\
\hline
\end{tabular}

Table 3. Deflection of the femoral head in the proximal-distal direction, measured by LVDT-PD (Fig. 3) for the 12 loading configurations. Average \pm standard deviation between six test repetitions is reported, in millimeters. Positive values indicate a displacement of the femoral head towards proximal. As different load values were applied for the different loading configurations, to enable comparisons, the readouts were all scaled to a conventional load of $1 \mathrm{BW}$ applied to the femoral head.

\begin{tabular}{cccc}
\hline & \multicolumn{3}{c}{ Internal rotation } \\
\cline { 2 - 4 } Adduction & $0^{\circ}$ & $15^{\circ}$ & $30^{\circ}$ \\
\hline $0^{\circ}$ & $0.110 \pm 0.006 \mathrm{~mm}$ & $0.116 \pm 0.004 \mathrm{~mm}$ & $0.137 \pm 0.001 \mathrm{~mm}$ \\
$10^{\circ}$ & $0.151 \pm 0.010 \mathrm{~mm}$ & $0.175 \pm 0.007 \mathrm{~mm}$ & $0.181 \pm 0.009 \mathrm{~mm}$ \\
$20^{\circ}$ & $0.172 \pm 0.003 \mathrm{~mm}$ & $0.181 \pm 0.006 \mathrm{~mm}$ & $0.183 \pm 0.004 \mathrm{~mm}$ \\
$30^{\circ}$ & $0.200 \pm 0.005 \mathrm{~mm}$ & $0.228 \pm 0.003 \mathrm{~mm}$ & $0.215 \pm 0.003 \mathrm{~mm}$ \\
\hline
\end{tabular}

surface varied by over $70 \%$, depending on the direction of the applied force. Furthermore, the direction of principal strain depended on the loading direction; variations of over $45^{\circ}$ of the principal strain direction were observed between different loading configurations, in regions where strain exceeded 100 microstrain. The configuration of $30^{\circ}$ internal rotation and $30^{\circ}$ adduction generated the largest strain in the head/neck region. 


\section{Zani et al.}

Table 4. Reaction torque about the femoral long axis at the distal extremity measured by the torsional load cell (Fig. 3) for the 12 loading configurations. Average \pm standard deviation between six test repetitions is reported, in Nm. Positive values indicate an internal reaction torque applied at the distal end. As different load values were applied for the different loading configurations, to enable comparisons, the readouts were all scaled to a conventional load of $1 \mathrm{BW}$ applied to the femoral head.

\begin{tabular}{cccc}
\hline & \multicolumn{3}{c}{ Internal rotation } \\
\cline { 2 - 4 } Adduction & $0^{\circ}$ & $15^{\circ}$ & $30^{\circ}$ \\
\hline $0^{\circ}$ & $17.35 \pm 0.06 \mathrm{Nm}$ & $12.06 \pm 0.03 \mathrm{Nm}$ & $5.22 \pm 0.05 \mathrm{Nm}$ \\
$10^{\circ}$ & $17.54 \pm 0.14 \mathrm{Nm}$ & $11.98 \pm 0.06 \mathrm{Nm}$ & $5.08 \pm 0.15 \mathrm{Nm}$ \\
$20^{\circ}$ & $16.41 \pm 0.01 \mathrm{Nm}$ & $11.32 \pm 0.13 \mathrm{Nm}$ & $4.95 \pm 0.03 \mathrm{Nm}$ \\
$30^{\circ}$ & $15.23 \pm 0.01 \mathrm{Nm}$ & $10.51 \pm 0.02 \mathrm{Nm}$ & $4.66 \pm 0.01 \mathrm{Nm}$ \\
\hline
\end{tabular}

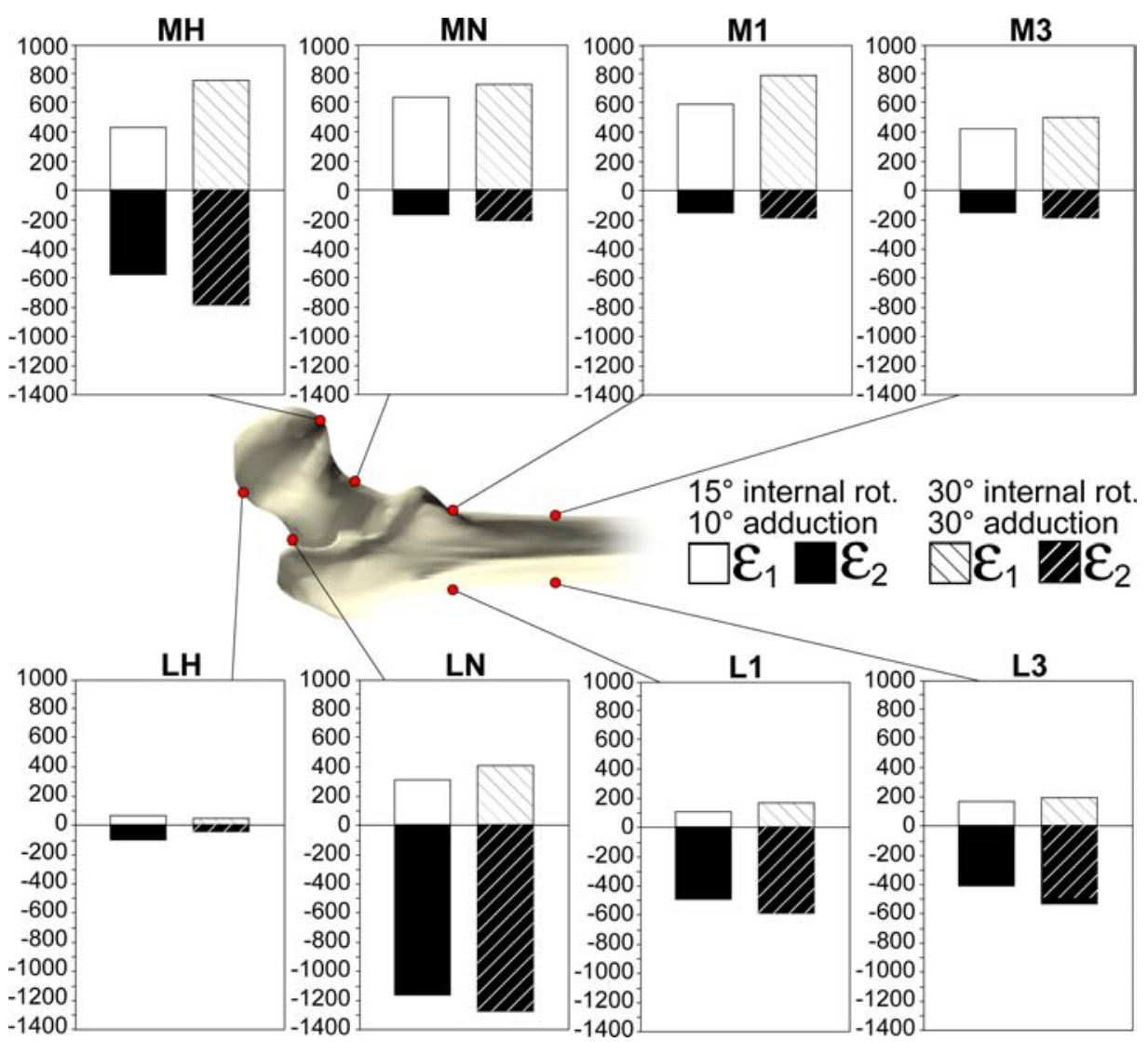

Fig. 6. Maximum and minimum principal strains $\left(\varepsilon_{1}\right.$ and $\varepsilon_{2}$, in microstrain) on the medial and lateral sides of the femur. Average and standard deviation between six test repetitions is reported for two loading configurations: $15^{\circ}$ internal rotation and $10^{\circ}$ adduction, and $30^{\circ}$ internal rotation and $30^{\circ}$ adduction (this configuration generated the largest strain in the head/neck region). The error bars for the standard deviation are hardly visible as the tests were highly repeatable. As different load values were applied for the different loading configurations, to enable comparisons, the strain values were all scaled to a conventional load of $1 \mathrm{BW}$ applied to the femoral head. 


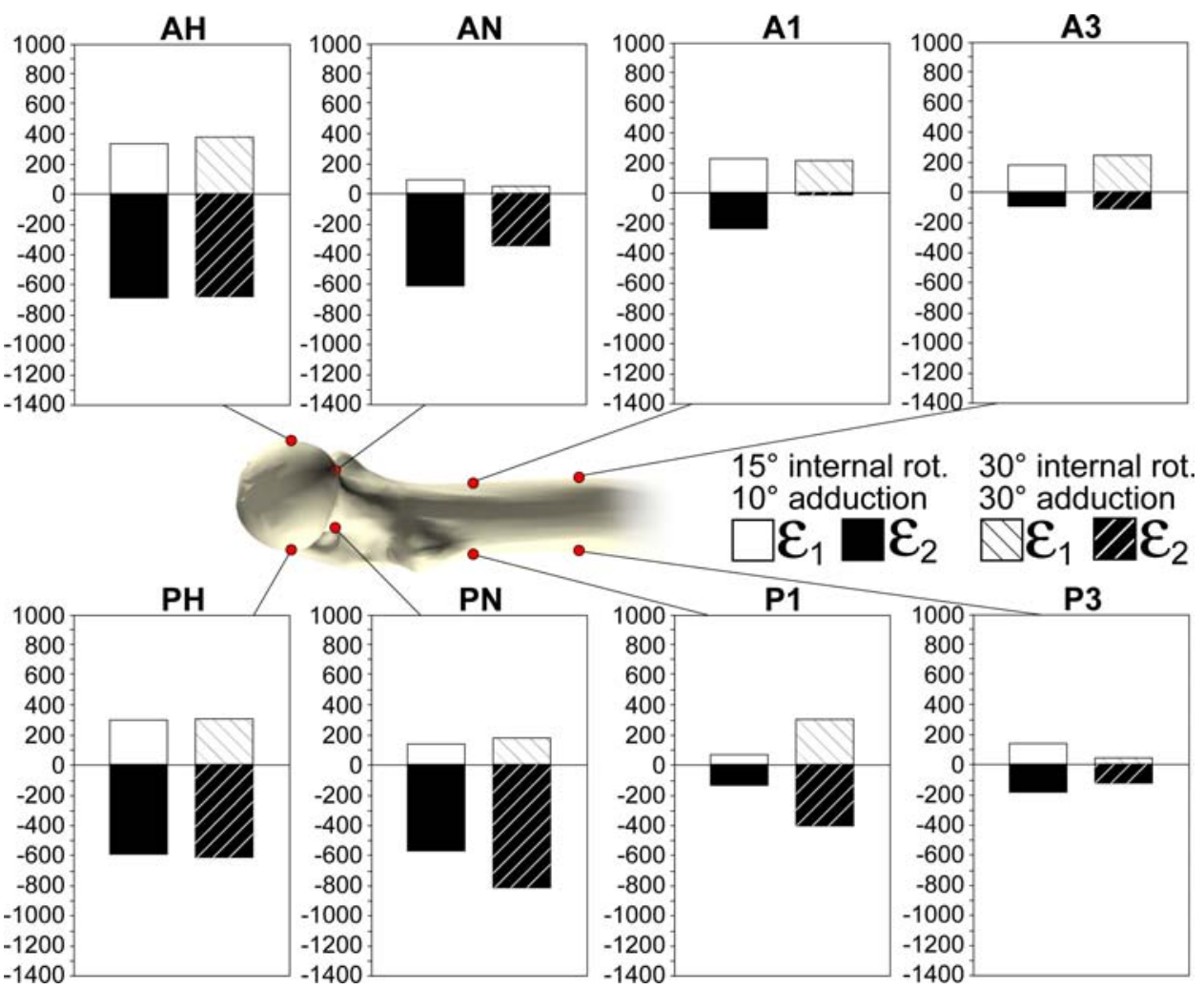

Fig. 7. Maximum and minimum principal strains $\left(\varepsilon_{1}\right.$ and $\varepsilon_{2}$, in microstrain) on the anterior and posterior sides of the femur. Average and standard deviation between six test repetitions is reported for two loading configurations: $15^{\circ}$ internal rotation and $10^{\circ}$ adduction, and $30^{\circ}$ internal rotation and $30^{\circ}$ adduction (this configuration generated the largest strain in the head/neck region). The error bars for the standard deviation are hardly visible as the tests were highly repeatable. As different load values were applied for the different loading configurations, to enable comparisons, the strain values were all scaled to a conventional load of $1 \mathrm{BW}$ applied to the femoral head.

\subsection{Destructive testing}

The destructive test was successfully carried out, with all the signals (load, displacement and strain) being sampled up to failure. The high-speed video enabled identification of the point of fracture initiation (Fig. 8): fracture occurred as a typical base-of-the-neck fracture, which initiated in the inferior side of the neck.

\section{Discussion}

The aim of this work was to replicate in vitro the load applied to the proximal femur during sideways fall with a dedicated protocol that should overcome the limitations of previous studies.

An in vitro setup was developed, which allowed accurate application of the desired components of load, while eliminating any other component of force. This enabled 
L. Zani et al.

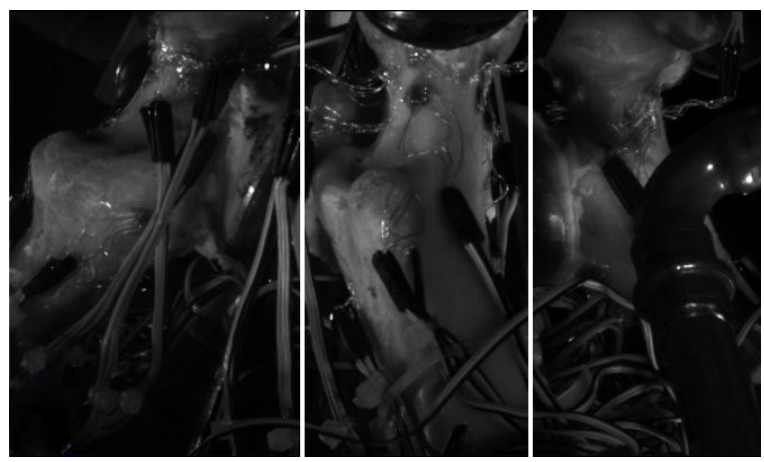

(a)

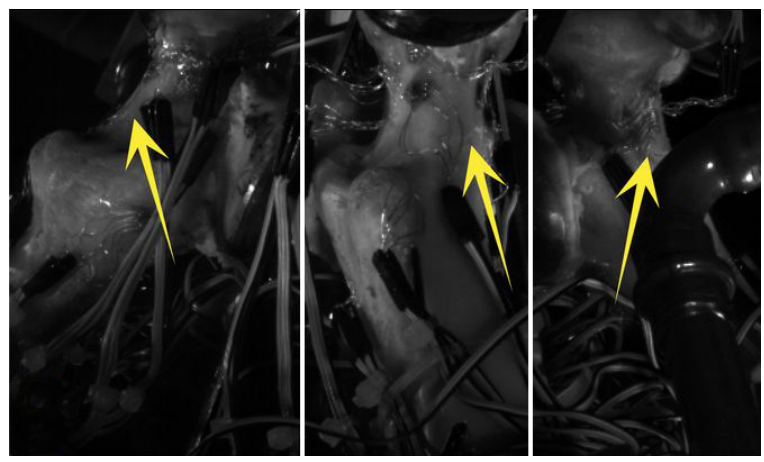

(b)
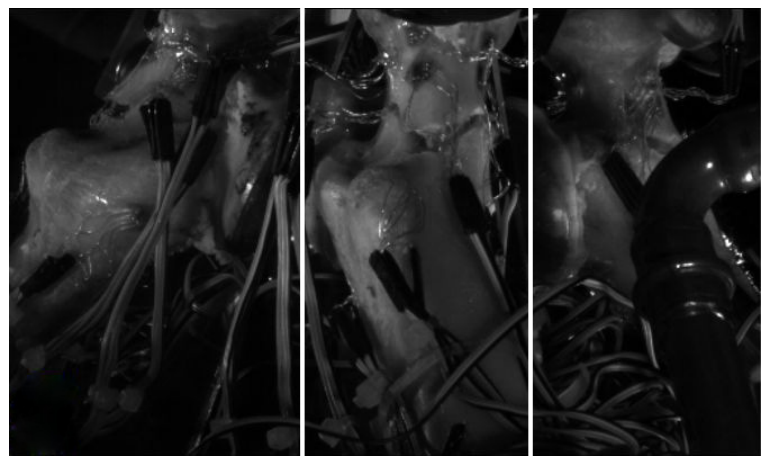

(c)

Fig. 8. Frames obtained from the high-speed movie during the destructive test of a left femur. The image in the center of each picture is a direct view of the femoral neck from the medial side; the ones on the left and right (postero-lateral and antero-lateral) are reflected images obtained from the two mirrors placed next to the femur and suitably oriented (Fig. 4). Picture A shows the femur shortly before the first signs of fracture are seen $(0.4 \mathrm{~ms}$ before Picture B). Picture B shows the instant when the crack can first be seen (inferior part of the neck, indicated by the yellow pointers). Picture C ( $0.9 \mathrm{~ms}$ after Picture B) shows a later stage of propagation. The pictures have low resolution ( 1 pixel = approximately $0.2 \mathrm{~mm}$ on the physical specimen) because they were acquired by the high-speed camera. 
overcoming limitations of previous studies, ${ }^{31,32}$ where, in addition to the desired load, additional unknown load components were delivered by an over-constrained loading setup. At the same time, the loading setup included an additional load cell to measure the torque about the long axis of the femur. The information provided by such a load cell complemented the information from the load cell of the testing machine, by recording the actual torque while the femur was loaded non-destructively and to failure. This solution is similar to the one proposed by Courtney et al., where a transducer recorded the torque delivered to the femoral diaphysis. ${ }^{45}$

To avoid over-constraining the femur, the setup allowed a number of degrees of freedom. Displacements/rotations were monitored by displacement and rotation transducers. This overcame a limitation of most previous setups, where only the displacement of the actuator was recorded. ${ }^{31,32}$ In our setup, information was available for all three components of translation of the head of the femur, and for the tilt of the femur in a vertical plane while loaded.

Signals from all the transducers above were highly repeatable, indicating that the setup provided an excellent control on the applied load, and enabled consistent measurement of the loading conditions, of the structural deflections and of the strain pattern on the bone surface. Measurement repeatability has been seldom reported in the past for this type of loading. Differences between different loading configurations were $2-3$ orders of magnitude larger than the variability between repetitions, confirming the significance of the effect of the direction of the applied loads.

To measure the state of strain, the bone surface was instrumented with 16 triaxial strain gauges measuring principal strains and the direction of principal strains. This enabled overcoming another limitation of the majority of previous studies. In fact, most published experimental studies reported only the failure load, while the strain distribution was not measured. Only Lang et al. ${ }^{31}$ measured the strain distribution in a proximal femur when a sideways fall was simulated. Direct comparisons are difficult, as the nine strain gauges used by Lang et $a l .{ }^{31}$ were at different locations than those used in our study. However, if strains are compared for the same loading configuration (30 internal rotation; $30^{\circ}$ adduction), similar trends could be observed: (1) the largest tensile strains in both cases were measured on the medial side; (2) the largest compressive strains were measured on the lateral side; (3) on average, strains were similar at the head and neck regions, and slightly lower at the level of the lesser trochanter.

The setup proposed in this study enabled loading the same bone specimen at different angles: the internal-external rotation angle could be adjusted within $+/-90^{\circ}$, while the adduction angle could be adjusted in the range $0^{\circ}-50^{\circ}$ (the range $0^{\circ}$ to $30^{\circ}$ was actually tested in this study for both angles). This is extremely important, as the direction of the loads applied to the femur during sideways fall is absolutely unpredictable. Conversely, in the literature, in most cases only one configuration is tested (15 ${ }^{\circ}$ internal rotation; $10^{\circ}$ adduction. ${ }^{5,14-21}$ ) Exploring a range of possible directions (while measuring bone strains) can be a useful means of identifying which direction of the applied force is most critical for bone integrity. In fact, the displacement of the femoral head, and the value and direction of principal 
strains at the same location on the femur surface varied greatly depending on the direction of the applied force. To the authors' knowledge, such an exploratory in vitro investigation has never been carried out before. The results obtained from the femur tested in this study show that the direction of the applied load could have a significant effect on the strain values. The present findings also demonstrate that the direction of the applied load can significantly alter the strain distribution, so that the most stressed point is different for different direction of the applied loads.

The main limitation of this study is that currently only one femur specimen has been tested. This prevents drawing any conclusions related to the biomechanics of loading of the proximal femur, and to the fractures associated to sideways falls. However, the tests carried out so far were sufficient to assess the effectiveness and repeatability of the setup, and to confirm the existence of different strain distributions in relation to different loading angles.

In conclusion, this study has shown that a new paradigm for testing the proximal femur (including improved testing conditions and a variety of loading configurations) can provide more accurate and more extensive information about the state of strain in the proximal femur.

\section{Acknowledgments}

The authors wish to thank Paolo Erani, Nicola Brandolini and Filip Pogrzeba for the technical support; Fulvia Taddei for the stimulating discussions; and Luigi Lena for the artwork. This study was co-funded by the European Community co-funded this study ("The Osteoporotic Virtual Physiological Human — VPHOP" grant FP7-ICT2008-223865) and by Regione Emilia-Romagna (Region-University Research Program 2007-2009).

\section{References}

1. Brauer CA, Coca-Perraillon M, Cutler DM, Rosen AB, Incidence and mortality of hip fractures in the United States, J Am Med Assoc 302:1573-1579, 2009.

2. Meling T, Harboe K, Søreide K, Incidence of traumatic long-bone fractures requiring inhospital management: A prospective age- and gender-specific analysis of 4890 fractures, Injury 40:1212-1219, 2009.

3. Parkkari J, Kannus P, Palvanen M, Natri A, Vainio J, Aho H, Vuori I, Jarvinen M, Majority of hip fractures occur as a result of a fall and impact on the greater trochanter of the femur: A prospective controlled hip fracture study with 206 consecutive patients, Calcif Tissue Int 65:183-187, 1999.

4. Hayes WC, Myers ER, Morris JN, Gerhart TN, Yett HS, Lipsitz LA, Impact near the hip dominates fracture risk in elderly nursing home residents who fall, Calcif Tissue Int 52:192-198, 1993.

5. Backman S, The proximal end of the femur: Investigations with special reference to the etiology of femoral neck fractures; anatomical studies; roentgen projections; theoretical stress calculations; experimental production of fractures, Acta Radiol Suppl 1-16, 1997.

6. Berry SD, Miller RR, Falls: Epidemiology, pathophysiology, and relationship to fracture, Curr Osteoporosis Rep 6:149-154, 2008. 
7. De Bakker PM, Manske SL, Ebacher V, Oxland TR, Cripton PA, Guy P, During sideways falls proximal femur fractures initiate in the superolateral cortex: Evidence from high-speed video of simulated fractures, J Biomech 42:1917-1925, 2009.

8. Pinilla TP, Boardman KC, Bouxsein ML, Myers ER, Hayes WC, Impact direction from a fall influences the failure load of the proximal femur as much as age-related bone loss, Calcif Tissue Int 58:231-235, 1996.

9. McCreadie BR, Goldstein SA, Biomechanics of fracture: Is bone mineral density sufficient to assess risk? J Bone Miner Res 15:2305-2308, 2000.

10. Oden ZM, Selvitelli DM, Bouxsein ML, Effect of local density changes on the failure load of the proximal femur, J Orthop Res 17:661-667, 1999.

11. Van den Kroonenberg AJ, Hayes WC, McMahon TA, Dynamic models for sideways falls from standing height, J Biomech Eng 117:309-318, 1995.

12. Van den Kroonenberg AJ, Hayes WC, McMahon TA, Hip impact velocities and body configurations for voluntary falls from standing height, J Biomech 29:807-811, 1996.

13. Nankaku M, Kanzaki H, Tsuboyama T, Nakamura T, Evaluation of hip fracture risk in relation to fall direction, Osteoporosis Int 16:1315-1320, 2005.

14. Bauer JS, Kohlmann S, Eckstein F, Mueller D, Lochmuller EM, Link TM, Structural analysis of trabecular bone of the proximal femur using multislice computed tomography: A comparison with dual X-ray absorptiometry for predicting biomechanical strength in vitro, Calcif Tissue Int 78:78-89, 2006.

15. Boehm HF, Horng A, Notohamiprodjo M, Eckstein F, Burklein D, Panteleon A, Lutz J, Reiser M, Prediction of the fracture load of whole proximal femur specimens by topological analysis of the mineral distribution in DXA-scan images, Bone 43:826-831, 2008.

16. Bouxsein ML, Coan BS, Lee SC, Prediction of the strength of the elderly proximal femur by bone mineral density and quantitative ultrasound measurements of the heel and tibia, Bone 25:49-54, 1999.

17. Bouxsein ML, Courtney AC, Hayes WC, Ultrasound and densitometry of the calcaneus correlate with the failure loads of cadaveric femurs, Calcif Tissue Int 56:99-103, 1995.

18. Cheng XG, Lowet G, Boonen S, Nicholson PH, Brys P, Nijs J, Dequeker J, Assessment of the strength of proximal femur in vitro: Relationship to femoral bone mineral density and femoral geometry, Bone 20:213-218, 1997.

19. Courtney AC, Wachtel EF, Myers ER, Hayes WC, Effects of loading rate on strength of the proximal femur, Calcif Tissue Int 55:53-58, 1994.

20. Eckstein F, Lochmuller EM, Lill CA, Kuhn V, Schneider E, Delling G, Muller R, Bone strength at clinically relevant sites displays substantial heterogeneity and is best predicted from site-specific bone densitometry, J Bone Miner Res 17:162-171, 2002.

21. Eckstein F, Wunderer C, Boehm H, Kuhn V, Priemel M, Link TM, Lochmüller E-M, Reproducibility and side differences of mechanical tests for determining the structural strength of the proximal femur, J Bone Miner Res 19:379-385, 2004.

22. Cristofolini L, Viceconti M, Towards the standardization of in vitro load transfer investigations of hip prostheses, J Strain Anal Eng Des 34:1-15, 1999.

23. Cristofolini L, Metti C, Viceconti M, Stress patterns induced by press-fitting and by external loads in cementless hip arthroplasty measured with photoelastic coatings, J Strain Anal Eng Des 38:289-301, 2003.

24. Fung Y-C, Bone and Cartilage, Biomechanics - Mechanical Properties of Living Tissues, Springer-Verlag, Berlin, pp. 383-415, 1980.

25. Roesler H, The history of some fundamental concepts in bone biomechanics, $J$ Biomech 20:1025-1034, 1987.

26. Cristofolini L, McNamara BP, Freddi A, Viceconti M, In-vitro measured strains in the loaded femur: Quantification of experimental error, J Strain Anal Eng Des 32:193-200, 1997. 
27. Field RE, Rushton N, Proximal femoral surface strain gauge analysis of a new epiphyseal prosthesis, J Biomed Eng 11:123-129, 1989.

28. Crick D, Wagner J, Bourgois R, Dehu P, Comportement mécanique de l'épiphyse supérieure de fémur resurfacé et incidence des variations anatomiques et des différentes types de cupules, Acta Orthop Belg 51:168-178, 1985.

29. Juszczyk M, Cristofolini L, Kaniuk J, Schileo E, Viceconti M, A novel method for determining the time and location of abrupt fracture initiation in bones, J Strain Anal Eng Des 45:481-493, 2010.

30. Lotz JC, Cheal EJ, Hayes WC, Fracture prediction for the proximal femur using finite element models: Part I-Linear analysis, J Biomech Eng 113:353-360, 1991.

31. Lang TF, Keyak JH, Heitz MW, Augat P, Lu Y, Mathur A, Genant HK, Volumetric quantitative computed tomography of the proximal femur: Precision and relation to bone strength, Bone 21:101-108, 1997.

32. Lotz JC, Hayes WC, The use of quantitative computed tomography to estimate risk of fracture of the hip from falls, J Bone Joint Surg Am 72:689-700, 1990.

33. Keyak JH, Kaneko TS, Tehranzadeh J, Skinner HB, Predicting proximal femoral strength using structural engineering models, Clin Orthop Relat Res 219-228, 2005.

34. Cristofolini L, Juszczyk M, Taddei F, Viceconti M, Strain distribution in the proximal human femoral metaphysis, Proc Inst Mech Eng H 223:273-288, 2009.

35. Ruff CB, Hayes WC, Cross-sectional geometry of pecos pueblo femora and tibiae - A biomechanical investigation: I. Method and general patterns of variation, Am J Phys Anthropol 60:359-381, 1963.

36. Cristofolini L, Anatomical reference frames for long bones: Biomechanical applications, in: Preedy VR (ed.), Handbook of Anthropometry: Physical Measures of Human Form in Health and Disease, Springer, New York, 2012.

37. Bayraktar HH, Morgan EF, Niebur GL, Morris GE, Wong EK, Keaveny TM, Comparison of the elastic and yield properties of human femoral trabecular and cortical bone tissue, J Biomech 37:27-35, 2004.

38. Bergmann G, Graichen F, Rohlmann A, Hip contact forces during stumbling, Langenbecks Arch Surg 389:51-59, 2004.

39. Bergmann G. Charite - Universitaetsmedizin Berlin "OrthoLoad", Retrieved 1 June 2010, from http://www.OrthoLoad.com.

40. Raftopoulos D, Katsamanis E, Saul F, Liu W, Saddemi S, An intermediate loading rate technique for the determination of mechanical properties of human femoral cortical bone, J Biomed Eng 15:60-66, 1993.

41. Cristofolini L, Conti G, Juszczyk M, Cremonini S, Van Sint Jan S, Viceconti M, Structural behaviour and strain distribution of the long bones of the human lower limbs, $J$ Biomech 43:826-835, 2010.

42. Keyak JH, Rossi SA, Jones KA, Les CM, Skinner HB, Prediction of fracture location in the proximal femur using finite element models, Med Eng Phys 23:657-664, 2001.

43. Cristofolini L, Juszczyk M, Martelli S, Taddei F, Viceconti M, In vitro replication of spontaneous fractures of the proximal human femur, J Biomech 40:2837-2845, 2007.

44. Viceconti M, Toni A, Giunti A, Strain gauge analysis of hard tissues: Factors influencing measurements, in: Little EG (ed.), Experimental Mechanics: Technology Transfer Between High Tech Engineering and Biomechanics, Elsevier, New York, pp. 177-184, 1992.

45. Courtney AC, Wachtel EF, Myers ER, Hayes WC, Age-related reductions in the strength of the femur tested in a fall-loading configuration, $J$ Bone Joint Surg Am 77:387-395, 1995 . 